\title{
Income, Time Effects and Direct Preferences in a Multimodal Choice Context: Application of Mixed RP/SP Models with Non-Linear Utilities
}

\author{
Elisabetta Cherchi • Juan de Dios Ortúzar
}

(C) Springer Science + Business Media, LLC 2006

\begin{abstract}
Transport problems typically involve at least two types of constraints, on income and on time. Therefore, the indirect utility function depends either on the income available after having subtracted the cost of the discrete alternative and on the free time left after having worked and travelled by each competing option. In the typical linear-in-the-attributes and in-the-parameters specification, that represents the first grade approximation of the indirect utility function, the effect of income and time constraints cancel out and only the cost and time of the alternatives matter in the comparison between them. From a microeconomic point of view this is equivalent to assume that income and time effects could be disregarded; which is not always the case. To account for these effects the utility function should include second order attributes; however, in non-linear utility functions it may not be easy to distinguish among several effects that could be relevant: direct preferences for good and leisure, and simple interactions between attributes other than income and time effects. This paper analyses these effects from a theoretical point of view focusing on the possible confounding problem in detecting income and time effects. We use a dataset collected for a modal choice context and containing both revealed and stated preference data, and estimate several NL models examining the effect of the different second-order terms on detecting income and time effects. We compared specifications including square
\end{abstract}

\footnotetext{
E. Cherchi $(\bowtie)$

CRiMM-Dipartimento di Ingegneria del Territorio,

Facoltà di Ingegneria-Università di Cagliari,

Piazza d'Armi, 16-09123 Cagliari, Italy

e-mail: echerchi@unica.it

J. de D. Ortúzar

Departamento de Ingeniería de Transporte,

Pontificia Universidad Católica de Chile,

Casilla 306, Cod. 105 Santiago 22, Chile

e-mail: jos@ing.puc.cl
} 
cost and time attributes, interactions between time and cost, cost divided by the income available to be spent on free time, and time multiplied by free time. Our results confirm the strong effect of direct preferences for goods and leisure time on choice, and the potential confounding effect between quadratic attributes and other non-linear omitted terms. Finally, we also found that care should be taken in highlighting income and time effects using mixed data sources, since confounding effects can occur when non-linearities are accounted for in both data sets.

Keywords Income and time effects $\cdot \mathrm{RP} / \mathrm{SP}$ data $\cdot$ Non-linearities

\section{Introduction}

The specification of the systematic utility in discrete choice models, namely the attributes to be introduced into a model and their form, is a basic step in the search for the best model to simulate a phenomenon under study. The most attractive approach to define the utility function is certainly a theoretical one (Train and McFadden, 1978; Jara-Díaz and Farah, 1987), since it gives the possibility of constructively using economic theory to suggest and justify, in behavioural terms, how to incorporate attributes into the functional form. The increasing attention that theoretical approaches have received in recent years is also reinforced by the fact that random utility models are derived from assumptions about consumer behaviour; therefore a theoretical approach is consistent with their mathematical structure.

A theoretical approach involves defining a microeconomic formulation to describe personal behaviour and maximising direct utility under a set of constraints. Transport problems typically involve at least two types of constraints: an income and a time constraint. Therefore, the indirect utility function conditional upon the choice of a certain discrete alternative depends either on the income available after having subtracted the cost of the discrete alternative, and on the free-time left after having worked and travelled by this option. The passage from the direct to the modal or route utility function is a crucial element in the definition of the utility specification. In fact, in the majority of cases it implies approximations that diminish the model's explanatory power and, maybe more importantly, do not allow to account for important effects that influence and often determine individual choices. The most typical example is the linear-in-theattributes and in-the-parameters specification that represents the first grade approximation of the indirect utility function. In this linear function the effect of income and time constraints cancel out, and only the cost and time of each alternative matter in the comparison between alternatives. From a microeconomic point of view, this approximation is equivalent to assume that income and time effects could be disregarded; which is not always the case.

The objective of this paper is to gain a deeper insight into the effects of income and time constraints on mode choice model estimation. In Section 2 the microeconomic derivation of the conditional indirect utility is reviewed, highlighting the importance of the non-linearity assumptions in detecting income and time effects. Section 3 describes briefly the methodology adopted for building the data bank and Section 4 illustrates the model estimation results, highlighting those 
involved in the theoretical analyses developed. Finally, Section 5 summarizes our conclusions.

\section{Microeconomic Derivation of Modal Utility}

The basic concept underlying microeconomic theory is the rationality postulate, ${ }^{1}$ according to which the consumer "always chooses the one he prefers from a set of available options" (Varian, 1978). The underlying hypothesis is that the attractiveness of an alternative can be measured in quantitative terms as a function of its attributes using a scalar defining a single objective function. To each available option and hence to each possible choice, the consumer associates a utility function that translates to the level of satisfaction $\mathrm{s} / \mathrm{he}$ derives from it.

In the transport context, the basic assumptions (Train and McFadden, 1978) are that individuals derive utility from the quantity of goods they can achieve and from the time they can spend on leisure activities:

$$
\begin{array}{ll} 
& U(G, L) \\
\text { s.t } \quad & G+c_{j}=I+\omega W \quad \forall j \in M \\
& L+t_{j}+W=T
\end{array}
$$

where $G$ and $L$ are, respectively, the goods bought and leisure time spent on a reference period $T, I$ is the fixed income (i.e., not depending on the number of hours worked, $W)^{2}$ available to be spent on period $T ; \omega$ is the individual wage rate; $c_{j}$ and $t_{j}$ are, respectively, the cost and time of travelling by alternative $j$ in the reference period T. $M$ is the set of modes (alternatives) available. ${ }^{3}$

The optimum consumption of continuous goods, conditional upon the fact that the user has chosen a discrete good $j$, gives the indirect utility function typically used in discrete choice model:

$$
V_{j} \cong U\left(I-c_{j}, \omega, T-t_{j}\right)
$$

In the most general case, i.e., even without assigning a specific form to the direct utility, it is clear that the systematic utility in Eq. (2) is a function of income minus cost (i.e., on the income left after having paid for that alternative) and also a function of the time available to be spent after having travelled. The major problem is how to specify the microeconomic problem in order to detect the presence of income and/or time effects and, eventually, account for them. In fact, some assumptions made for Eq. (1) implicitly assume a fixed marginal utility for income and time. Moreover, in the most general case the indirect utility (2) has

\footnotetext{
${ }^{1}$ In the sense that the statement cannot be demonstrated but is taken to be true.

${ }^{2}$ In the Train and McFadden (1978) formulation income is given by $\omega W+E$, where $E$ is the endowment, i.e., a source of money not related to work. As it has no effect on our discussion, for simplicity we consider here that $E=0$, but we assume that income from work can have two components: one fixed $(I)$ and another one that varies with the number of hours worked and can be chosen freely by each individual. This is a simple generalisation that turns out useful for our analysis.

${ }^{3}$ In the above problem we are making the assumption that the period $T$ corresponds to the period for just one trip. For bigger reference periods we need to include all the trips made in the period (Jara-Díaz, 1998).
} 
not a form that can be used directly in a discrete choice model and therefore some approximations (e.g., through Taylor expansion) are typically required, that can again imply fixed marginal utilities of income and time.

Jara-Díaz and Farah (1987) demonstrate that if we model the choice of individuals that can decide how many hours to work at a given wage rate (expressed in equation (1) by the term $\omega W$ ) we cannot account for income effect. In fact, "although in applied work $\omega$ is approximated by $I / W \ldots$ the specification of $V_{j}$ is derived assuming that earned income is basically determined endogenously ... which implies a constant marginal utility of income and constant value of time" (Jara-Díaz and Farah, 1987). In fact, the Train and McFadden approach yields the following modal utility specification:

$$
V_{j}=-\lambda c_{j} / \omega+\theta_{t} t_{j}
$$

where $\lambda$ is the marginal utility of income (MUI) and $\theta_{t}$ is the weight parameter for travel time.

Conversely, they demonstrated that when individuals cannot choose freely working time (i.e., in equation (1) $\omega W=0$ ) the indirect utility function representing such behaviour is similar to that in Eq. (3) but the implicit wage rate dividing modal cost is replaced by an expenditure rate $g=I /(T-W)$ i.e., by the amount the individual earns per unit of disposable leisure time (DLT): ${ }^{4}$

$$
V_{j}=-\lambda c_{j} / g+\theta_{t} t_{j}
$$

In the expenditure rate formulation of Jara-Díaz and Farah (1987) income (I) is endogenously defined, reflecting purchasing power; therefore its presence in the modal utility specification is related to the presence of income effect in mode choice, indicating that the $M U I=-\lambda / g$ varies with income. As hihglighted by Jara-Díaz and Videla (1989) ... "this phenomenon is the discrete choice counterpart of the income effect."

Here, we would like to note two things. Firstly, as $g=I /(T-W)$ the MUI depends not only on income but also on free time, and is bigger for those with higher income and smaller for people who have little free time. Secondly, Eq. (4), as Eq. (3), is one of several equivalent forms for the modal utility. The key point is that the modal utility typycally used in discrete choice models is only the relevant part for mode choice of the indirect utility. In fact, as discrete choice models work on comparison, all terms in the utility function not depending on the alternatives drop. As it does not matter how we scale utility, the following modal utilities are indeed equivalent:

$$
\begin{aligned}
& V_{j}=-\lambda c_{j} / g+\theta_{t} t_{j} \\
& V_{j}=-\lambda c_{j}+\theta_{t} t_{j} g \\
& V_{j}=-\lambda c_{j} / I+\theta_{t} t_{j} /(T-W)
\end{aligned}
$$

\footnotetext{
${ }^{4}$ In the formulation of Jara-Díaz and Farah DLT is the total time $T$ minus the working time $W$. As the working hours cannot be maximized if the income constraint $\omega W=0$ operates they subtract the total time in the time constraint.
} 
Although they are equivalent, it is interesting to note that expressions (5b) and (5c) make it clearer that the expenditure rate might also have an effect on the marginal utility of time varying with the disposable leisure time. As for the income effect (Jara-Díaz and Ortúzar, 1989)... "whether this effect is strong or weak is a matter of empirical scrutiny through model estimation using this specification." Moreover, expression (5c) reveals that in the linear specification what really matters in modal utility is the incidence of travel cost on disposable income $\left(c_{j} / I\right)$, and the incidence of travel time on disposable leisure time $\left(t_{j} /(T-W)\right)$.

The effect of $P I=c_{j} / I$ and $P T=t_{j} /(T-W)$ for a second order approximation of the indirect utility function were shown by Jara-Diaz (1990). Using a CobbDouglas direct utility function with generic parameters $\gamma$ and $\beta$, and a secondorder Taylor expansion around $(I, T-W)$, he obtained the following expression for the truncated indirect utility:

$$
\bar{V}_{j}=-\gamma \underbrace{\left[1+\frac{\beta}{2} P I-\frac{\beta}{2} P T\right]}_{\alpha_{c}} \frac{c_{j}}{g}-\beta \underbrace{\left[1-\frac{\gamma}{2} P I+\frac{\gamma}{2} P T\right]}_{\alpha_{t}} t_{j}
$$

In particular, he demonstrates that if $P T$ and $P I$ give very small values, $\alpha_{c}=\alpha_{t}=$ 1 , the weights of cost and time in mode choice can be attributed simply to direct preferences $\left(\gamma\right.$ and $\beta$ ). In this case, Eq. (6) reduces to $V_{j}=-\gamma c_{j} / g-\beta t_{j}$, which implies that a linear function would be adequate. Moreover, if $c_{j}<<I$ and $t_{j}<T-W$, from Eq. (5c) we can also add that a simple linear in cost and time specification $\left(V_{j}=-\gamma c_{j}+\beta t_{j}\right)$ would be appropriate.

Conversely, if $P T$ and $P I$ are significantly different from zero, Jara-Díaz (1990) notes that a second order utility function should be more appropriate as quadratic time and/or cost terms allow capturing income and time effects. In fact, Jara-Díaz and Videla (1989) demonstrate also that a simple cost squared term can act as a first condition to detect the presence of income effect, as it allows ascertaining whether indirect utility is, in general, a function of income. In fact, it would be:

$$
\begin{gathered}
V_{j}=-\lambda c_{j}+0.5 \lambda_{2} c_{j}^{2}+\ldots \\
M U I=\lambda-\lambda_{2} c_{j}
\end{gathered}
$$

and a significant positive value of $\lambda_{2}$ indicates that the MUI varies as a function of the cost of the alternative, telling us that individual preferences are sensitive to the amount of cost spent travelling. However, how sensitive they are depends on the level of each individual income; therefore, income needs to be accounted for, somehow, in the utility function.

From Eq. (6) it is clear that if the incidence of travel cost on disposable income and/or similarly the incidence of travel time on disposable leisure time is not negligible, then income and/or time effects should not be disregarded. However, there are at least two aspects that deserve consideration. Firstly the effect of significant proportions of disposable income or leisure time is reduced or increased by the effect of the direct preference parameters for goods and leisure time. In fact, let us think for example of individuals that show a stronger direct preference for goods $(\gamma)$ rather than for leisure time $(\beta)$; even if the value of PI is big, when this is combined with a low value in the direct preference it could result 
in $\alpha_{c}=1$, and this would imply an absence of income effect. At the same time, a strong direct preference for goods could make the time squared term significant even for low values of PT. The opposite happens for a major direct preference for leisure time. Interestingly, the interaction terms could result significant in the presence of strong preferences either for goods or leisure time.

Secondly, having $P T$ and $P I$ proportions significantly different from zero also lead to interaction effects between cost and time, and these need to be explicitly accounted for in order to highlight income and time effects. For example, Cherchi and Ortúzar (2003a) show that when non-linearities are included in the utility function, confounding effects could sometimes drive researchers to wrong conclusions. In particular they found that a significant positive value for the coefficient of the cost squared term was just acting as proxy for interaction terms omitted from the specification.

An important point to be highlighted is that most of the research discussed above has concerned income effect, and then moved into the domain of timerelated decisions under the basic economic theory that views time as a resource comparable to money. However, some studies on time (see for example Leclerc et al., 1995) argue that consumers do not treat time like money. In fact, although time is a scarce resource, and as such is perceived as having value and capable of being bought and spent, it cannot be stored and the time lost or saved cannot as easily be transferred (i.e., recuperated or applied) to new situations as money can. In fact, Leclerc et al. (1995) found that, differently from what is postulated in the economic theory of time, the individual assessment of time is highly contextdependent, and is influenced by the value of the outcome of certain situations (in their case it was the outcome of waiting time). At the same time, although individuals demonstrate a tendency to avoid risk for time as well as for money when making decisions, the aversion is significantly higher in the case of timerelated decisions. Finally, individuals are also sensitive to multiple losses or gains of time as well as of money, but again the response is different: when people are given a choice about a timing prospect they prefer to integrate time rather than to segregate it.

Time-related decisions seem therefore quite complex as several other effects can arise and most of them cannot be explained under the typical economic theory of time. While Leclerc et al. (1995) have set out specific experiments to reveal these effects, a major problem might be to detect and distinguish them in real cases. Nevertheless, all the above results suggest that variability is likely to be found in the case of travel time parameters and that sources of variability other than (or instead of) time effect and direct preferences for good and leisure should be expected.

\section{Databank}

Data were collected in 1998 for a modal choice context among car, bus and train users for suburban trips in and out of Cagliari, the capital of Sardinia. The method used for building the data bank (Cherchi and Ortúzar, 2002) incorporated three types of surveys. A qualitative survey using focus groups for gaining a good understanding of the phenomenon and to test delicate issues (e.g., how to ask for 
income); a revealed preference (RP) survey describing current trips and a stated preference (SP) survey to evaluate the introduction of a new commuter option.

The RP survey was conducted on a sample of 300 families living in the corridor, randomly extracted from the telephone directory. A 24-hour travel diary survey was filled in personally by each respondent, but all interviews were assisted from the first contact to completion by an interviewer who was also responsible for gathering socio-economic information. As the survey used self-completion forms, major attention was placed on making them as clear and user-friendly as possible. Questionnaires were not difficult but long, since they could contain up to a maximum of ten trips described in considerable detail. They were designed to reduce the typical small trip not reporting bias (erroneously judged as irrelevant by respondents). A detailed check of the answers was made immediately after collection and in case of major errors or incomprehensible information, the family was contacted by phone and asked for clarification. A few checks were also made in order to eliminate round-off errors (e.g., the arrival and departure times had to be consistent with the sum of the duration of each part of the trip); this allowed us to ensure high precision in the information regarding times, either related to travel or any other activities performed during the day. This turned out to be very important for the analysis on the effect of free time.

The last piece of information asked by the interviewer on the RP survey was the income variable. Net personal income (NPI) was divided into ten classes, ranging from no income to an open upper class corresponding to more than 1,800 Euros. Specific questions were included in the RP survey to evaluate how much money students (who do not earn money) had to spend; we found that they did not always had a fixed monthly stipend, but their life style and therefore their modal choice, varied significantly depending on their family's income.

A sample of 524 people was obtained, yielding a total of 1,840 reported trips. After many tests (to ensure that only people who really had a choice were included) a final sample of just 338 individuals was left to be used in model estimation, reflecting the current structure of demand.

The third survey, on stated preferences (SP), was conducted for $90 \%$ of the 338 people mentioned above. It basically had two objectives: to expand the RP data bank and to check commuter responses to the introduction of a new train alternative (i.e., the current train service but with far superior characteristics). We opted for a choice experiment between the proposed new train service and the current transport mode since almost the entire population used only two modes, car and bus. Furthermore, a choice experiment appeared more appropriate for the combined use of SP and RP data, because preferences are expressed in a context similar to an RP survey.

The SP design was customised to ensure greater realism. The design included four variables at three levels (trip time, cost, frequency and comfort) for the bus users design; and three variables at three levels (trip time, cost and frequency) and one variable (comfort) at two levels, for the car user's design. One major objective of the SP experiment was to include interaction effect and to study their influence on mode choice. Having four variables at three levels allows to estimate two-term interactions between cost, frequency and travel time, and thus to also account for the non-additive effects of variables in the analysis. In order to estimate three twoterm interactions with four variables, 27 hypothetical situations must be used (Louviere et al., 2000) so a block design was used to reduce them just to nine for 
Table 1 Some socio-economic variables for the sample

\begin{tabular}{|c|c|c|c|c|c|c|c|c|}
\hline & \multicolumn{3}{|c|}{ NPI } & DLT & \multicolumn{3}{|c|}{ PI (NPI) } & $\mathrm{PT}$ \\
\hline Median & \multicolumn{3}{|c|}{258.23} & 74.00 & \multicolumn{3}{|c|}{0.13} & 0.21 \\
\hline Mean & \multicolumn{3}{|c|}{666.43} & 76.33 & \multicolumn{3}{|c|}{0.20} & 0.21 \\
\hline St. error & \multicolumn{3}{|c|}{522.69} & 11.14 & \multicolumn{3}{|c|}{0.20} & 0.10 \\
\hline \multirow[t]{3}{*}{$\mathrm{CV}$} & \multicolumn{3}{|c|}{0.78} & 0.15 & \multicolumn{3}{|c|}{0.97} & 0.44 \\
\hline & \multicolumn{4}{|c|}{ RP sample } & \multicolumn{4}{|c|}{ SP sample } \\
\hline & NPI & DLT & PI (NPI) & PT & NPI & DLT & PI (NPI) & PT \\
\hline Median & 774.69 & 74.00 & 0.10 & 0.17 & 258.23 & 74.00 & 0.15 & 0.22 \\
\hline Mean & 780.45 & 77.18 & 0.15 & 0.19 & 632.66 & 76.08 & 0.22 & 0.22 \\
\hline St. error & 600.92 & 12.54 & 0.15 & 0.12 & 492.43 & 10.68 & 0.21 & 0.09 \\
\hline $\mathrm{CV}$ & 0.77 & 0.16 & 0.99 & 0.60 & 1.91 & 0.14 & 0.94 & 0.40 \\
\hline
\end{tabular}

(*) Income is in Euros. At the time of the survey (1998), 1 Euro $=0.90$ USD.

each respondent (Caussade et al., 2005). Both designs were divided into three blocks randomly generated without repetition and the order of presentation of the situations inside each block was also randomised.

The final mixed RP/SP data set used for the model estimation, contained 1,396 observations and it was composed of $45 \%$ train users, $32 \%$ car users and $24 \%$ bus users. A more detailed description of both surveys can be found in Cherchi and Ortúzar (2002). Table 1 summarizes some socio-economic variables that are relevant for our analysis on income and time effects. We will discuss the content of this table in the next section.

\section{Results}

Based on the results of the microeconomic derivation of the conditional indirect utility, several second-order attributes (production variables, quadratic cost and/or time variables) were included and tested in the utility function. Other specifications, including explicitly income and/or available free time were also tested. All the models were estimated using ALOGIT (Daly, 1998). A detailed description of the type of variables specified can be found in Cherchi and Ortúzar (2002).

When RP and SP data are available the recommended approach to estimate choice models involves pooling both data sets to exploit their respective advantages and overcome their specific limitations (Ben-Akiva and Morikawa, 1990; Bradley and Daly, 1997). However, before estimating a mixed RP/SP model good practice advises that separate models for each data set should be estimated to detect which attributes are candidates to be generic in both sets (Louviere et al., 2000). We carried out this analysis (Cherchi and Ortúzar, 2005) and all the linear variables, except walking time, were considered good candidates for such a generic estimation. The same has to be done for the non-linear terms and particularly for the quadratic terms, as confounding effects among second-order variables as well as between RP and SP behaviour may lead to wrong conclusions about the presence of income and time effects.

iㅡㄹ Springer 
Table 2 shows the results of using only RP data (the first four models) and only SP data (the remaining six). First, it should be noted that the PI and PT values in Table 1 are almost the same in the RP and SP data sets. In particular they are a little bit higher for the SP data but still very small. The only difference appears in the coefficient of variation of PT, which is equal to 0.60 in the RP data and 0.40 in the other case.

None of the second-order terms was highly significant in the RP data set, neither the time and cost squared variables nor the interactions (model RP-NL1). Moreover, both the cost squared term and, what is more important, the linear cost term, had a wrong sign. Note that the wrong sign for the linear cost is due to the presence of the quadratic cost and not to the interactions. This result was not expected; in fact, although PI has a small average value in the RP sample, suggesting in principle that a linear utility function could be appropriate, its coefficient of variation is quite large $(\mathrm{CV}=0.99)$, implying a certain difference across individuals in the sample. Conversely, the time squared term has a correct sign but it is significant only at the $89 \%$ level (model RP-NL2), and the loglikelihood ratio test with respect to the linear model RP-NL3 is rejected at the $92 \%$ level. The significance of the quadratic time variable does not seem to be due to PT, as its mean and standard deviation in the RP data are particularly low. In line with this, the use of an expenditure rate model (model RP-NL4) leaves the model completely unchanged. Therefore, it seems that neither income nor time effects actually exist in our revealed preference data.

Conversely, in the SP data we found that all second-order terms are highly significant, but again both the linear and cost squared terms have a wrong sign (model SP-NL1), and this happen also if the quadratic cost term is the only second-order term in the model (model SP-NL2). Interestingly, the linear cost term becomes significant and with the right sign when the time squared term is included either with (model SP-NL3) or without the interaction terms. The linear cost term also becomes significant (without the time squared term) if an expenditure rate model is used (model SP-NL4), showing that the effect of the expenditure rate $(g)$ on cost is not due to income but maybe to free time. Moreover, if the time squared term is included with an expenditure rate specification (model SP-NL5), all the variables become more significant and the overall fit is improved (the LR test between models SP-NL4 and SP-NL5 is rejected at the $99 \%$ level). Finally, it is interesting to note that the specification in model SP-NL6, where cost was multiplied by $(T-W)$, gives exactly the same results as model SP-NL5, confirming that income is not really influencing choice. Interestingly, the overall fit of these two models is also almost equal to the loglikelihood obtained when estimating a model (SP-NL3) without including neither $g$ nor $(T-W)$; however, all the variables are more significant in the expenditure rate model and especially the cost term (the $t$-test for $c / g$ is equal to -2.4 , while it reduces to -1.8 if we use only $c$ ). This suggests that there is an influence of available leisure time on cost, beyond that between cost and travel time, which is captured by the specific interaction term. This also suggests that available leisure time needs to be explicitly taken into account, and that it may affect not only the preference for travel time.

As discussed in Section 2, a positive significant time squared parameter suggests the presence of time effect. However, the significance of the quadratic time variable in the SP environment was unexpected, as not only PT has a small 


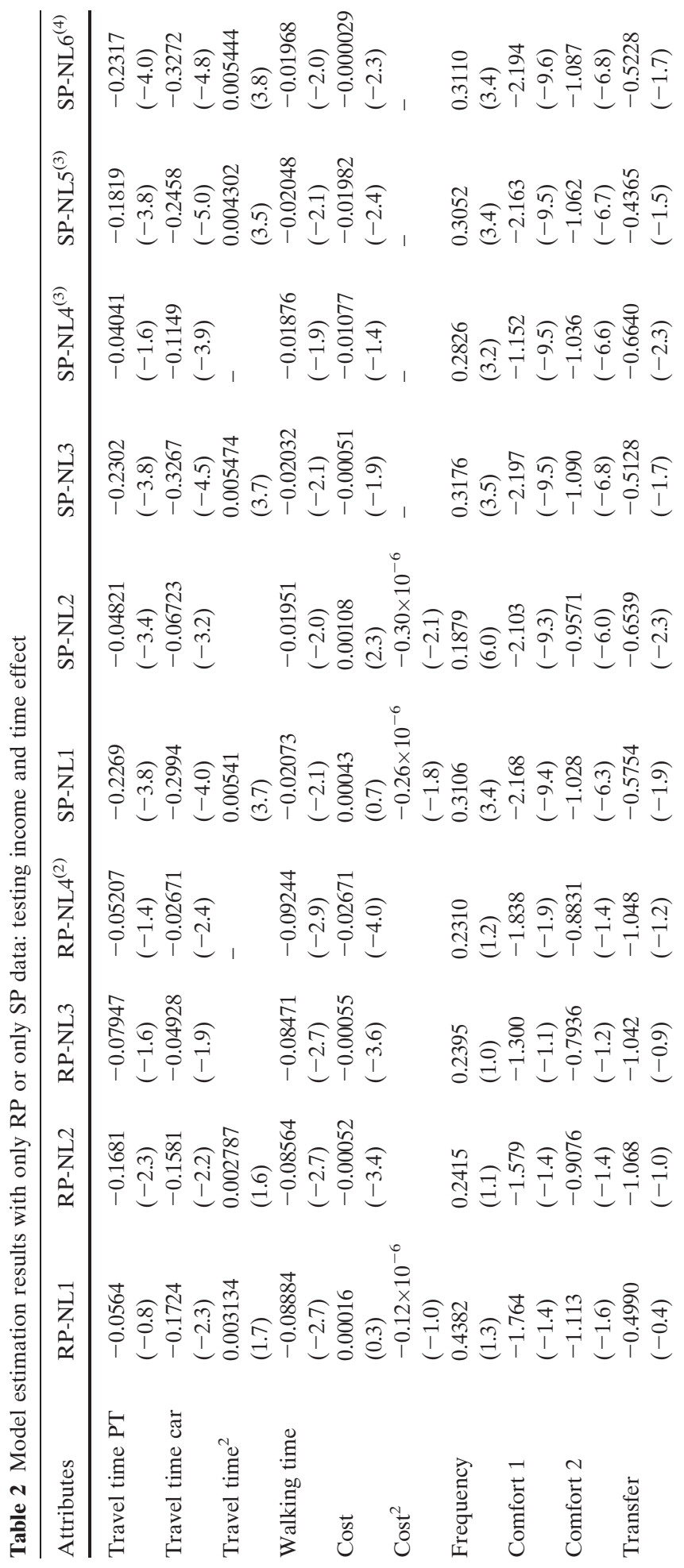




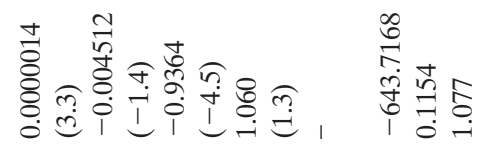

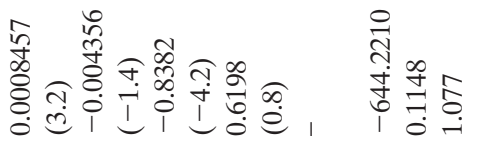

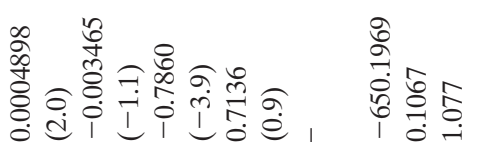

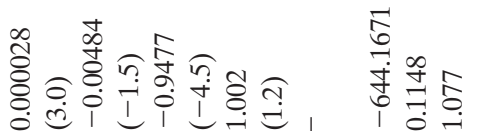

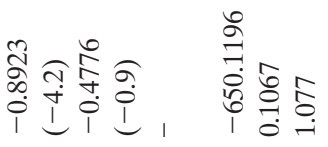

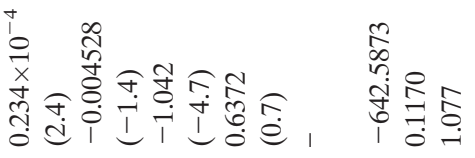

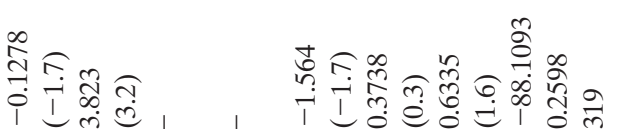

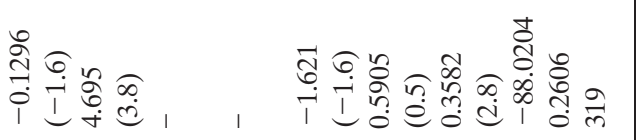

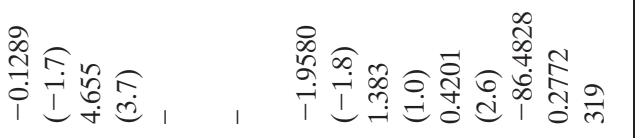

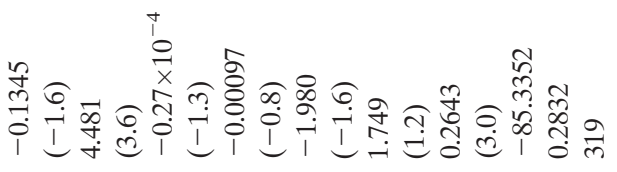

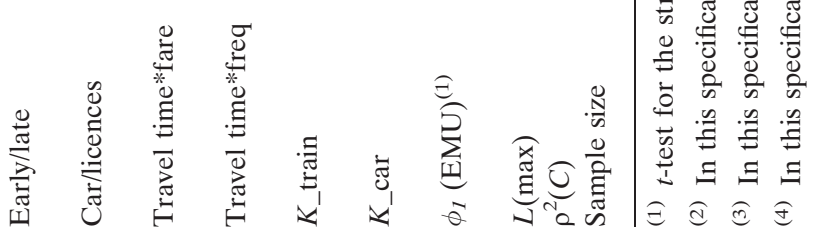


Table 3 Model estimation results with joint RP/SP data: testing income and time effect

\begin{tabular}{|c|c|c|c|c|c|c|}
\hline Attributes & NL1 & NL2 & NL3 & NL4 & NL5 & NL6 \\
\hline Travel time PT & $\begin{array}{l}-0.05228 \\
(-2.5)\end{array}$ & $\begin{array}{l}-0.1083 \\
(-3.2)\end{array}$ & $\begin{array}{l}-0.2099 \\
(-3.5)\end{array}$ & $\begin{array}{l}-0.1958 \\
(-3.5)\end{array}$ & $\begin{array}{l}-0.0564 \\
(-2.4)\end{array}$ & - \\
\hline Travel time car & $\begin{array}{l}-0.1034 \\
(-2.4)\end{array}$ & $\begin{array}{l}-0.2413 \\
(-3.2)\end{array}$ & $\begin{array}{l}-0.3315 \\
(-3.7)\end{array}$ & $\begin{array}{l}-0.2967 \\
(-3.9)\end{array}$ & $\begin{array}{l}-0.1307 \\
(-2.7)\end{array}$ & - \\
\hline Travel time ${ }^{2}$ & - & - & $\begin{array}{l}0.00505 \\
(3.3)\end{array}$ & $\begin{array}{l}0.004616 \\
(3.3)\end{array}$ & - & - \\
\hline $\begin{array}{l}\text { Travel time }{ }^{2} \\
\quad(\mathrm{SP})\end{array}$ & - & $\begin{array}{l}0.00275 \\
(2.7)\end{array}$ & - & - & - & - \\
\hline $\begin{array}{l}\text { Travel time } \\
\quad(\leq 10 \mathrm{~min})\end{array}$ & - & - & - & - & - & $\begin{array}{l}-0.6832 \\
(-3.2)\end{array}$ \\
\hline $\begin{array}{l}\text { Travel time PT } \\
\qquad(>10 \mathrm{~min})\end{array}$ & - & - & - & - & - & $\begin{array}{l}-0.07021 \\
(-2.3)\end{array}$ \\
\hline $\begin{array}{l}\text { Travel time } \\
\text { car }(>10 \\
\min )\end{array}$ & - & - & - & - & - & $\begin{array}{l}-0.1867 \\
(-3.3)\end{array}$ \\
\hline $\begin{array}{l}\text { Walking time } \\
\text { (RP) }\end{array}$ & $\begin{array}{l}-0.2123 \\
(-3.9)\end{array}$ & $\begin{array}{l}-0.2307 \\
(-3.6)\end{array}$ & $\begin{array}{l}-0.1776 \\
(-3.5)\end{array}$ & $\begin{array}{l}-0.1821 \\
(-3.5)\end{array}$ & $\begin{array}{l}-0.2221 \\
(-3.7)\end{array}$ & $\begin{array}{l}-0.2201 \\
(-3.5)\end{array}$ \\
\hline $\begin{array}{l}\text { Walking time } \\
\quad(\mathrm{SP})\end{array}$ & $\begin{array}{l}-0.02945 \\
(-1.8)\end{array}$ & $\begin{array}{l}-0.0233 \\
(-1.7)\end{array}$ & $\begin{array}{l}-0.02528 \\
(-2.0)\end{array}$ & $\begin{array}{l}-0.0309 \\
(-2.1)\end{array}$ & $\begin{array}{l}-0.03822 \\
(-1.9)\end{array}$ & $\begin{array}{l}-0.04534 \\
(-2.2)\end{array}$ \\
\hline Cost & $\begin{array}{l}-0.00033 \\
(-1.4)\end{array}$ & $\begin{array}{l}-0.0010 \\
(-2.3)\end{array}$ & $\begin{array}{l}-0.00086 \\
(-2.8)\end{array}$ & $\begin{array}{l}-0.03283 \\
(-3.3)\end{array}$ & $\begin{array}{l}-0.00114 \\
(-2.5)\end{array}$ & $\begin{array}{l}-0.03922 \\
(-3.0)\end{array}$ \\
\hline $\operatorname{Cost}^{2}(\mathrm{SP})$ & - & $\begin{array}{l}0.17 \times 10^{-6} \\
(1.5)\end{array}$ & $\begin{array}{l}0.63 \times 10^{-7} \\
(0.7)\end{array}$ & - & $\begin{array}{l}0.36 \times 10^{-6} \\
(2.3)\end{array}$ & - \\
\hline Frequency & $\begin{array}{l}0.2761 \\
(2.5)\end{array}$ & $\begin{array}{l}0.3923 \\
(2.4)\end{array}$ & $\begin{array}{l}0.3590 \\
(3.0)\end{array}$ & $\begin{array}{l}0.4055 \\
(3.3)\end{array}$ & $\begin{array}{l}0.3229 \\
(3.1)\end{array}$ & $\begin{array}{l}0.4844 \\
(3.4)\end{array}$ \\
\hline Comfort 1 & $\begin{array}{l}-2.661 \\
(-2.9)\end{array}$ & $\begin{array}{l}-2.038 \\
(-2.5)\end{array}$ & $\begin{array}{l}-2.137 \\
(-3.3)\end{array}$ & $\begin{array}{l}-2.506 \\
(-3.6)\end{array}$ & $\begin{array}{l}-3.321 \\
(-3.6)\end{array}$ & $\begin{array}{l}-3.32 \\
(-3.7)\end{array}$ \\
\hline Comfort 2 & $\begin{array}{l}-1.297 \\
(-2.7)\end{array}$ & $\begin{array}{l}-1.056 \\
(-2.4)\end{array}$ & $\begin{array}{l}-1.083 \\
(-3.1)\end{array}$ & $\begin{array}{l}-1.251 \\
(-3.6)\end{array}$ & $\begin{array}{l}-1.686 \\
(-3.3)\end{array}$ & $\begin{array}{l}-1.664 \\
(-3.4)\end{array}$ \\
\hline Transfer & $\begin{array}{l}-0.8859 \\
(-1.9)\end{array}$ & $\begin{array}{l}-0.6383 \\
(-2.7)\end{array}$ & $\begin{array}{l}-0.6223 \\
(-1.9)\end{array}$ & $\begin{array}{l}-0.6874 \\
(-1.9)\end{array}$ & $\begin{array}{l}-0.8661 \\
(-1.8)\end{array}$ & $\begin{array}{l}-0.8684 \\
(-2.0)\end{array}$ \\
\hline Early/late (RP) & $\begin{array}{l}-0.2970 \\
(-3.3)\end{array}$ & $\begin{array}{l}-0.2456 \\
(-2.5)\end{array}$ & $\begin{array}{l}-0.1882 \\
(-2.5)\end{array}$ & $\begin{array}{l}-0.1849 \\
(-2.5)\end{array}$ & $\begin{array}{l}-0.2513 \\
(-2.9)\end{array}$ & $\begin{array}{l}-0.18 \\
(-2.2)\end{array}$ \\
\hline $\begin{array}{l}\text { Car/licences } \\
\text { (RP) }\end{array}$ & $\begin{array}{l}8.381 \\
(2.8)\end{array}$ & $\begin{array}{l}15.650 \\
(3.0)\end{array}$ & $\begin{array}{l}11.10 \\
(3.4)\end{array}$ & $\begin{array}{l}9.297 \\
(3.5)\end{array}$ & $\begin{array}{l}12.25 \\
(3.0)\end{array}$ & $\begin{array}{l}11.96 \\
(3.3)\end{array}$ \\
\hline $\begin{array}{l}\text { Travel time* } \\
\text { fare (SP) }\end{array}$ & - & $\begin{array}{l}0.000024 \\
(2.8)\end{array}$ & $\begin{array}{l}0.000031 \\
(3.3)\end{array}$ & $\begin{array}{l}0.001213 \\
(3.5)\end{array}$ & - & - \\
\hline $\begin{array}{l}\text { Travel time } \\
\quad * \text { freq }(\mathrm{SP})\end{array}$ & - & $\begin{array}{l}-0.0078 \\
(-2.0)\end{array}$ & $\begin{array}{l}-0.0063 \\
(-2.2)\end{array}$ & $\begin{array}{l}-0.00666 \\
(-2.3)\end{array}$ & - & - \\
\hline $\begin{array}{l}\text { Travel } \\
\text { time*fare } \\
(\mathrm{SP})(>10 \\
\text { min })\end{array}$ & - & - & - & - & - & $\begin{array}{l}0.001291 \\
(3.0)\end{array}$ \\
\hline $\begin{array}{r}\text { Travel time } \\
* \text { freq(SP) } \\
(>10 \mathrm{~min})\end{array}$ & - & - & - & - & - & $\begin{array}{l}-0.006433 \\
(-2.0)\end{array}$ \\
\hline $\begin{array}{l}K \_ \text {train } \\
(\mathrm{RP}+\mathrm{SP})\end{array}$ & $\begin{array}{l}-0.7973 \\
(-2.4)\end{array}$ & $\begin{array}{l}-0.6892 \\
(-2.3)\end{array}$ & $\begin{array}{l}-0.8522 \\
(-2.9)\end{array}$ & $\begin{array}{l}-0.9093 \\
(-2.9)\end{array}$ & $\begin{array}{l}-0.8811 \\
(-2.4)\end{array}$ & $\begin{array}{l}1.153 \\
(1.5)\end{array}$ \\
\hline$K \_$car $(\mathrm{RP}+\mathrm{SP})$ & $\begin{array}{l}0.3935 \\
(0.5)\end{array}$ & $\begin{array}{l}1.791 \\
(2.0)\end{array}$ & $\begin{array}{l}1.471 \\
(2.0)\end{array}$ & $\begin{array}{l}1.179 \\
(1.7)\end{array}$ & $\begin{array}{l}0.060 \\
(0.1)\end{array}$ & $\begin{array}{l}-1.189 \\
(-3.0)\end{array}$ \\
\hline
\end{tabular}


Table 3 (Continued)

\begin{tabular}{lllllll}
\hline Attributes & \multicolumn{1}{c}{ NL1 } & NL2 & NL3 & NL4 & NL5 & \multirow{2}{*}{ NL6 } \\
\hline$\phi_{1}(\text { EMU })^{(1)}$ & 0.3243 & 0.2439 & 0.3933 & 0.4347 & 0.2985 & 0.3165 \\
& $(5.8)$ & $(9.1)$ & $(4.5)$ & $(3.8)$ & $(6.8)$ & 6.33 \\
$\phi_{2}$ (SP factor $_{\text {scale) }[\ldots]^{(1)}}$ & 0.7566 & 1.056 & 1.024 & 0.8536 & 0.6060 & 0.6312 \\
& $(2.7)$ & $(2.5)$ & $(3.3)$ & $(3.6)$ & $(3.4)$ & $(3.6)$ \\
$L(\max )$ & {$[0.88]$} & {$[0.12]$} & {$[0.08]$} & {$[0.62]$} & {$[2.2]$} & 2.08 \\
$\rho^{2}(C)$ & -746.9893 & -733.3604 & -728.5622 & -727.9505 & -741.3403 & -718.8014 \\
Sample size & 0.1334 & 0.1492 & 0.1548 & 0.1555 & 0.1400 & 0.1662 \\
& 1,396 & 1,396 & 1,396 & 1,396 & 1,396 & 1,396 \\
\hline
\end{tabular}

average value but it also has a rather low variation among individuals $(\mathrm{CV}=0.40)$. To try to understand this phenomenon we tested three more specifications. The first accounted explicitly for the time constraint, i.e., including the square term $(T-W-t)$, but results were not superior to the specifications described above. A second model was specified with the time variables divided by $(T-W-t)$, but again results were not superior to those discussed above. Finally, the third specification included dummy variables that allow for different time and cost parameters depending on the proportion of free-time spent travelling $(\mathrm{PT} \leq 0.21)$. The overall fit was better, but some results were counterintuitive. In particular, we found that if individuals have more free time they evaluate the time spent travelling by car $14 \%$ higher than those who have less free time, which is counterintuitive. Public transport users instead, have correctly a bigger marginal utility of time ( $37 \%$ more) if they have less free time.

Some considerations arise from these analyses. Firstly, the significance of the quadratic time variable does not seem to be simply caused by PT or by the time constraint. Also, the fact that both the quadratic time term and the interactions appear significant, while the quadratic cost term is not, seems to confirm that individuals show a strong preference for goods. Moreover, since the linear cost term becomes significant only when the quadratic time variable is included, suggests that the presence of the former allows to reveal the preference for goods better. Note that the same is not evident if only interactions are included [Eq. (6)], as their effect is split between $\alpha_{c}$ and $\alpha_{t}$.

As we have RP and SP data, the best approach is to go for a joint estimation. Following the results in Table 2 all attributes, including the alternative specific constants, were specified RP/SP generic except walking time and the interactions terms (the latter were included only in the SP alternatives). In particular, it is important to mention that the walking time variable was not included in the car alternative for the SP data. A detailed discussion of the ASC and walking time specifications is provided by Cherchi and Ortúzar (2006).

Table 3 reports the results from the mixed RP/SP models. First note that any non-linear utility specification is more significant than their linear counterpart (model NL1). In particular, both the quadratic time variable and the interactions (models NL2 and NL3) are highly significant (more than 99\% of significance) and with the right sign, while the cost squared term (specific only for the SP data) is not significant. However, contrary to the estimations with only one data set, it shows a correct positive sign as required by the microeconomic conditions (Jara- 
Díaz and Videla, 1989). Two more things are interesting to highlight. First, although the quadratic time variable was not significant in the RP data set, model NL3 with the RP/SP generic quadratic time variable is better than model NL2 where this variable is included only in the SP set. Second, the exclusion of the quadratic cost term leaves, as expected, the model completely unchanged (see model NL4).

The only misleading result is the quadratic cost variable that, when introduced in the joint RP/SP estimation as the only second order term, becomes highly significant and with the right positive sign (model NL5). All the other results confirm what we found when estimating separate models for each dataset. As for the quadratic time variable, it is not surprising that a generic RP/SP specification gives better result than when the variable was included only in the SP data. Firstly, although not highly significant, the effect of the quadratic time variable in the RP model was not negligible; secondly, in both data sets the significance of the quadratic time variable seems due to a stronger direct preference for goods rather than to a time effect. Therefore, it seems plausible that this effect is reinforced in the mixed estimation.

Although NL4 is not a bad model from a statistical point of view it fails to fulfil the microeconomic conditions of a negative marginal utility of time for almost $50 \%$ of the sample. This result is not surprising as it has been frequently reported in the literature (Revelt and Train, 1998; Brownstone, 2001; Cherchi and Ortúzar, 2003b; Cirillo and Axhausen, 2004; Sillano and Ortúzar, 2005), but such a model cannot be used for forecasting. We solved this problem estimating different travel time coefficients for short and long trips. The fact that individuals evaluate differently short and long trips has frequently been reported in the literature (Ortúzar, 1994; Gunn, 1996; Wardman, 1996; Gunn and Worsely, 1999); however, model NL6 means that in our sample (both sets), the evaluation of travel time is constant and equal for all modes, in the case of trips not longer than $10 \mathrm{~min}$. Conversely, for trips longer than 10 min not only the marginal utility of travel time varies between modes but it also interacts with both cost and frequency. In model NL6 the sample was divided with reference to the travel time of the chosen mode. It is interesting to note that for longer trips the marginal utility of travel time by car is more than twice that by public transport (PT); but as the PT system becomes better (i.e., as the frequency of PT increases) the marginal utility of travel time by both modes becomes closer. In particular, in our case they equate for a frequency of 18 vehicles per hour (i.e., a vehicle every $3 \mathrm{~min}$ ).

Note that a change in the bus or train frequency is also the policy that has the highest impact in demand forecast. As can be seen in Table 4, the percentage variation between the simulated and predicted market shares using model NL6 is larger when changes involve the frequency than for any other variables. Although an increase of $100 \%$ in the frequency might appear "too big," it is in reality a completely feasible policy. In fact, the actual frequency (especially for the train) is so low that doubling it means only an average frequency of $2-3$ trains/hour. Note also that a $57 \%$ increase in train demand means a share of just about $10 \%$, as the current train market share is very low. Finally note that reductions bigger than $20 \%$ for the travel time by train or for the bus fare appear as unfeasible policies in our case (i.e., the average actual value is less than $20 \mathrm{~min}$ for the travel time by train and less than 0.40 Euros for each trip by bus). 
Table 4 Percentage variation in demand predictions

\begin{tabular}{lcccc}
\hline Attributes & Percent of changes (\%) & \multicolumn{3}{c}{$\begin{array}{c}\text { Percentage of variation in demand } \\
\text { predictions by mode }\end{array}$} \\
\cline { 3 - 5 } & & Bus (\%) & Train (\%) & Car (\%) \\
\hline Train frequency & +20 & -3.6 & 12.4 & 0.0 \\
& +50 & -8.2 & 29.3 & -0.1 \\
Bus frequency & +100 & -15.8 & 57.4 & -0.3 \\
& +20 & 4.4 & -12.7 & -0.3 \\
Train travel time & +50 & 11.2 & -31.4 & -1.0 \\
Bus travel time & -100 & 21.5 & -56.5 & -2.5 \\
& -20 & -1.5 & 5.4 & 0.0 \\
Car travel time & -50 & 7.6 & -22.9 & -0.5 \\
& +20 & 12.9 & -37.7 & -1.0 \\
Train cost & +50 & 0.4 & 2.3 & -0.5 \\
& -20 & 2.7 & 4.6 & -1.9 \\
Bus cost & -50 & -1.2 & 3.7 & 0.0 \\
Car cost & -20 & -2.0 & 7.1 & 0.0 \\
& +20 & -0.3 & 1.2 & 0.0 \\
& +50 & 0.4 & 0.3 & -0.2 \\
& & 0.9 & 0.7 & -0.5 \\
\hline
\end{tabular}

Results from Table 4 also show that policies involving a reduction in the travel time by bus have a significant impact on both the bus and train demands (certainly bigger than changes in travel costs). However, it is important to remark that none of the policies involving an improvement in PT characteristics affect the market share of the car, except doubling the frequency of the bus. On the other hand, some reduction in the demand for car can be obtained by worsening some of its travel characteristics, in particular by increasing the travel time by car.

These results can be explained if we analyse separately the effect of these policies on market shares depending on the length of travel time and the alternatives available to each individual. Table 5 shows the percentage variation in demand for a $20 \%$ reduction in travel time by train, distinguishing between individuals whose travel time is up to $10 \mathrm{~min}$ and those who travel for more than $10 \mathrm{~min}$. Firstly it should be noted that the effect for short trips is more than twice that for longer trips. Secondly, a reduction in travel time by train for trips longer than $10 \mathrm{~min}$, affects those individuals who have also car available more (and note that in this

Table 5 Percentage variation in demand predictions for a $20 \%$ reduction in travel time by train

\begin{tabular}{llllc}
\hline & Alternatives available & \multicolumn{2}{c}{$\begin{array}{c}\text { Percentage of variation in demand } \\
\text { predictions by mode }\end{array}$} \\
\cline { 3 - 5 } & & Bus (\%) & Train (\%) & Car (\%) \\
\hline Train travel time ( $\leq 10 \mathrm{~min})$ & Bus, train, car & -2.2 & 72.7 & 0.0 \\
& Bus, train & -1.5 & 60.0 & -0.2 \\
Train travel time ( $>10 \mathrm{~min})$ & Bus, train, car & -2.9 & 30.0 & \\
& Bus, train & -4.8 & 12.7 & \\
\hline
\end{tabular}


case they would usually chose the car), rather than those who only have PT alternatives available.

\section{Conclusions}

An important issue in the specification of multimodal choice models is the possibility of using economic theory to justify the different underlying hypotheses in behavioural terms. This is always important for building a good model, but it is certainly crucial when some important effect, as that of income and/or time, needs to be accounted for. In this latter case, it has been demonstrated that a non-linear in the attributes utility function is needed; however care must be taken in judging the effect of second-order terms because some of these could lead to wrong conclusions.

In particular we found that care should be taken in highlighting income and time effects using mixed data sources, since confounding effects could occur when non-linearities were accounted for in both sets. Income and time effects should be tested separately in both data sets, because different interesting information may be drawn. In fact we found that direct preferences for goods and leisure time could play an important role in the effect of the second-order terms, reducing or increasing the effect of the proportion of cost and time spent on transport with respect to the budget available. We also found that the significance of quadratic cost and time variables could only be the result of the omission of interaction terms, suggesting that a full second order utility function needs to be at least tested (i.e., not only the quadratic terms).

Finally, we found that time-related decisions are quite complex, as several other effects other than time effects can arise. In our sample, we found that individuals evaluate differently short and long trips; but maybe more importantly, while for trips not longer than 10 min the evaluation of travel time is constant and equal for all modes, for trips longer than $10 \mathrm{~min}$, the marginal utility of travel time varies between modes but also interacts with both cost and frequency. In fact, the effect on the demand share for short trips is more than twice that for longer trips; morevoer, a reduction in travel time by train for trips longer than $10 \mathrm{~min}$ affect those individuals who have also the car available more than those who only have PT alternatives available. As a last comment, it is worth highlighting the importance of evaluating how models work in forecasting and not just their statistical results, especially when non-linearities are involved.

Acknowledgments We are grateful to Prof. Sergio Jara-Díaz, University of Chile for his inspiration and constructive comments and to Prof. Italo Meloni, University of Cagliari for his valuable support. Thanks are also due to the Chilean Fund for the Development of Scientific and Technological Research, through grant FONDECYT No. 1020981 and 1050672.

\section{References}

Ben-Akiva ME, Morikawa T (1990) Estimation of travel demand models from multiple data sources. Proceedings 11th International Symposium on Transportation and Traffic Theory, Yokohama, Japan

를 Springer 
Bradley MA, Daly AJ (1997) Estimation of logit choice models using mixed stated-preference and revealed-preference information. In: Stopher PR, Lee-Gosselin ME (eds), Understanding Travel Behaviour in an Era of Change. Pergamon, Oxford

Brownstone D (2001) Discrete choice modelling for transportation. In: Hensher DA (ed), Travel Behaviour Research: The Leading Edge. Pergamon, Amsterdam

Caussade S, Ortúzar J de D, Rizzi LI, Hensher DA (2005) Assessing the influence of design dimensions on stated choice experiment estimates. Transp Res 39B:621-640

Cherchi E, Ortúzar J de D (2002) Mixed RP/SP models incorporating interaction effects: modelling new suburban train services in Cagliari. Transportation 29:371-395

Cherchi E, Ortúzar J de D (2003a) Multimodal choice models with mixed RP/SP data: correlation, non-linearities and income effect. In: Selected Proceedings of the 9th World Conference on Transport Research, Pergamon, Amsterdam

Cherchi E, Ortúzar J de D (2003b) Alternative specific variables in non-linear utilities: influence of correlation, homoscedasticity and taste variations. 10th International Conference on Travel Behaviour Research (IATBR-2003), Lucerne, Switzerland

Cherchi E, Ortúzar J de D (2006) On fitting mode specific constants in the presence of new options in RP/SP models. Transp Res 40A:1-18

Cirillo C, Axhausen KW (2004) Evidence on the distribution of values of travel time savings from a six-week diary. Arbeitsbericht Verkehrs- und Raumplanung 212, IVT, ETH, Zurich

Daly AJ (1998) ALOGIT 3.8 User's Guide. Hague Consulting Group, The Hague

Gunn HF (1996) The 1985-1996 Dutch VOT Studies. In: Value of Time Seminar. PTRC, London

Gunn HF, Worsely T (1999) Implications of recent research into values-of-time for the classical transport model, forecast and appraisal. Proceedings 27th European Transport Conference, Cambridge, England

Jara-Díaz SR (1990) Valor subjetivo del tiempo y utilidad marginal del ingreso en modelos de partición modal. Apuntes de Ingeniería 39:41-49 (in Spanish)

Jara-Díaz SR (1998) A general micro-model of users' behaviour: the basic issues. In: Ortúzar J de D, Hensher DA, Jara-Díaz SR (eds), Travel behaviour research: updating the state of play, Elsevier Science, Oxford

Jara-Díaz SR, Farah M (1987) Transport demand and users' benefits with fixed income: the goods/leisure trade off revisited. Transp Res 21B:165-170

Jara-Díaz SR, Ortúzar J de D (1989) Introducing the expenditure rate in the estimation of mode choice models. Journal of Transport Economics and Policy 23:293-308

Jara-Díaz SR, Videla J (1989) Detection of income effect in mode choice: theory and application. Transp Res 23B:393-400

Leclerc F, Schmitt BH, Dubé L (1995) Waiting time and decision making: is time like money? J Consum Res 22:110-119

Louviere JJ, Hensher DA, Swait JD (2000) Stated choice methods: analysis and application. Cambridge University Press, Cambridge

Ortúzar, J de D (1994) Valor del Tiempo para Evaluación de Proyectos, Informe Ejecutivo para FONDECYT, Department of Transport Engineering, Pontificia Universidad Católica de Chile, Santiago (in Spanish)

Revelt D, Train KE (1998) Mixed logit with repeated choices: households' choice of appliance efficiency level. Rev Econ Stat 80:647-657

Sillano M, Ortúzar J de D (2005) Willingness-to-pay estimation with mixed logit models: some new evidence. Environ Plan 37A:525-550

Train KE, McFadden D (1978) The goods/leisure trade-off and disaggregate work trip mode choice models. Transp Res 12:349-353

Varian H (1978) Microeconomic analysis. Norton, New York

Wardman M (1996) Issues in model specification. In: Value of time seminar. PTRC, London 